\title{
Dosagem Laboratorial de Enzimas Musculares e Diagnóstico Equivocado de Polimiosite Juvenil: Problemas na Avaliação Clínica e na Fase Pré-Analítica ${ }^{*}$
}

\author{
Maria Mercedes Picarelli( ${ }^{(1)}$, Glória R.R.F. Kaiser ${ }^{(2)}$ e Carlos Alberto von Mühlen ${ }^{(3)}$
}

\section{INTRODUÇÃO}

A dosagem de enzimas musculares é a técnica laboratorial disponível mais específica para avaliação de dano muscular $^{(1,2,3)}$. Por ordem de especificidade, apresentam-se a creatinofosfoquinase (CPK), a aldolase, as transaminases e a lactato desidrogenase $(\mathrm{LDH})^{(2)}$. A análise em separado destes exames tem pouco valor diagnóstico, uma vez que estão presentes em outros tecidos como fígado, miocárdio e cérebro, além do músculo estriado. Mas, quando levadas em consideração em seu conjunto e associadas a um quadro clínico compatível com miopatia, são bastante confiáveis.

Existem fatores de interferência que podem provocar resultados falso-positivos ${ }^{(1)}$. Tais fatores incluem aqueles relacionados com a fase pré-analítica, ou seja, coleta e processamento da amostra, e aqueles relacionados com o uso de drogas e atividade física prévios à coleta ${ }^{(1,4)}$. A análise dos resultados deve levar em conta estes fatores tanto no momento do diagnóstico como no acompanhamento da resposta ao tratamento de uma miopatia inflamatória.

Algumas interferências podem ser significativas, particularmente na população infantil, como, por exemplo, a recomendação de evitar atividades físicas extenuantes nas 24 horas prévias à coleta ${ }^{(1,3)}$ ou a suspensão de drogas que possam interferir nos resultados, algumas de uso bastante comum (como aspirina ou ampicilina) ${ }^{(1)}$.

Descrevemos aqui dois casos de pacientes que receberam o diagnóstico de polimiosite juvenil a partir de dosagens muito alteradas de enzimas musculares, sem quadro clínico compatível. Também examinaremos as prováveis causas destas dosagens alteradas e revisaremos as normas para coletas adequadas de enzimas musculares. Salientamos que as queixas clínicas devem orientar o pedido de exames complementares na reumatologia.

\section{DESCRIÇÃO DE CASOS}

\section{CASO 1}

Paciente do sexo feminino, branca, com 3 anos de idade, 1 ano de evolução de quadro cutâneo generalizado com prurido, fotossensibilidade, lesões discrômicas em regiões de dobras, área cervical, dorso e cotovelos, com descamação leve e sem eritema. Queixas musculares ausentes. Também não se observavam lesões de Gottron ou heliótropo. A paciente tinha força muscular preservada e exame articular normal quando a examinamos. Diagnóstico pediátrico de dermatopolimiosite juvenil, sendo indicado tratamento com corticóide em dose elevada. Familiares contam que a coleta de material foi dificil, necessitou de várias tentativas e período prolongado de garroteamento. Trazia os seguintes resultados laboratoriais: FAN, fator reumatóide e anti-Jo 1 não reagentes. ECG e ecocardiograma normais, VSG $7 \mathrm{~mm}$ (Westergren), LDH 568 U/L (normal < 460), CPK 115 U/L (normal), aldolase 9,7 U/L (normal < 7,0). Em nova coleta com observação de Boas Práticas Laboratoriais obteve-se FAN negativo, anti Jo-1 ELISA não reagente, aldolase 5,8 U/L, CPK 120 U/L, LDH 217 U/L. Reavaliação dermatológica confirmou o diagnóstico de dermatite atópica.

\section{CASO 2}

Paciente do sexo feminino, branca, 4 anos de idade, com febre vespertina há 6 meses. Evoluiu com dificuldade de lateralizar a cabeça, artralgias e mialgias. Radiografia de seios da face mostrou sinusite, tratada com amoxicilina e clavulanato cerca de 4 semanas antes de a vermos. Avaliações neurológica e ortopédica prévias foram normais e a criança apresentou melhora progressiva da sintomatologia. Ao exame físico apresentava bom estado geral, ativa, sem

\footnotetext{
* Este trabalho contou com o apoio do Fundo de Auxílio à Pesquisa e Ensino em Reumatologia da Sociedade Brasileira de Reumatologia.

1. Médica reumatologista. Coordenadora do ambulatório de reumatologia pediátrica do Hospital São Lucas da PUCRS, Porto Alegre, RS.

2. Bioquímica do Metanalysis Centro de Diagnósticos Médicos, Porto Alegre, RS.

3. Professor titular de Reumatologia e Imunologia, Faculdade de Medicina da PUCRS, Porto Alegre, RS.
}

Endereço para correspondência: Carlos Alberto von Mühlen. Av. Carlos Gomes, 328/1009, Porto Alegre, RS, CEP 90480-000, e-mail: cavm@rocketmail.com 
lesões cutâneas, adenopatias ou organomegalias. $\mathrm{O}$ exame articular e da força muscular eram normais, inclusive da região cervical. A coleta de sangue nesta paciente havia sido traumática, sofrendo várias tentativas de punção e garroteamento prolongado, segundo a mãe. Obteve-se proteína $\mathrm{C}$ reativa não reagente, TGO 209 U/L (normal < 40), LDH 492 U/L (normal < 460), CPK fração MB 143 U/L, CPK 3.215 U/L, fator reumatóide e imunofluorescência para toxoplasmose não reagentes. A partir do diagnóstico clínico de polimiosite juvenil, foram prescritos corticóides em altas doses. Ao se repetir os exames com cuidados ao momento da coleta obteve-se aldolase 6,8 U/L (normal < 13), CPK $133 \mathrm{U} / \mathrm{L}$, LDH 200 U/L, provas de função da tireóide normais, antidsDNA não reagente, pesquisa negativa de anticorpos antisintetase por imunoprecipitação (dr. Ira Targoff, EUA) e ressonância magnética das quatro extremidades sem evidência de alterações. Como a criança estivesse assintomática, não recebeu medicação e permaneceu em observação por cerca de um ano, período em que tinha discretas parestesias de extremidades como única queixa, sem achados objetivos em avaliação neurológica.

\section{DISCUSSÃO}

A enzima CPK permanece como o exame laboratorial mais específico e provavelmente mais sensível para a avaliação de dano muscular ${ }^{(2,5)}$. Os outros marcadores musculares (aldolase, transaminases, enolase e LDH) têm especificidade e sensibilidade menores, e sua utilidade clínica é limitada se considerarmos seus valores de maneira isolada.

São fatores conhecidos de interferência nos resultados da $\mathrm{CPK}^{(1,3)}$ :

1. drogas como álcool, anfotericina $\mathrm{B}$, ampicilina, anticoagulantes, aspirina, colchicina, captopril, ácido aminocapróico, clofibrato, codeína, dexametasona, digoxina, furosemida, glutetimida, guanetidina, halotano, heroína, imipramina, carbonato de lítio, lovastatina, lidocaína, meperidina, morfina, propranolol, fenobarbital e succinilcolina podem aumentar os níveis de CPK.

2. gestação em período inicial, doença de Addison, hepatopatia, massa muscular pobre, neoplasias metastáticas, hipossecreção hipofisária anterior diminuem a CPK.

3. exercício físico intenso prévio à coleta ( 24 horas), procedimentos cirúrgicos e invasivos elevam a CPK.

4. injeções intramusculares até uma hora antes da coleta também elevam os níveis da enzima.

Em ambos os casos apresentados a descrição dos familiares confirma que os procedimentos de coleta foram considerados difíceis, com tempo prolongado de garroteamento e várias tentativas de punção. Ao examinarmos cada um dos fatores que poderiam ter provocado estas elevações, verificamos que os pacientes não estavam utilizando medicamentos listados como fonte de interferência. Também não havia ocorrido uso de injeções intramusculares ou procedimentos invasivos prévios à coleta.

Provocamos hemólise in vitro em coletas independentes de adultos em nosso laboratório, através da transferência abrupta do volume coletado e sem estar o bisel da agulha em contato com a parede do tubo (o oposto do orientado em boas práticas de coleta laboratorial). Verificamos que a elevação provocada com a hemólise não foi suficiente para explicar uma elevação tão importante como aquela verificada no caso 2 . Na primeira amostra independente testada os valores de CPK subiram de 64 para $87 \mathrm{U} / \mathrm{L}$ quando o tubo sofreu hemólise. $\mathrm{Na}$ segunda amostra houve elevação de 145 para $181 \mathrm{U} / \mathrm{L}$. Tais valores podem ser ainda maiores caso as amostras permaneçam à espera de processamento por algumas horas, o que não é incomum em laboratórios de patologia clínica com grandes rotinas.

Portanto, retrospectivamente, temos dificuldade em identificar qual o principal problema indutor dos erros verificados nos resultados de dois laboratórios distintos e de diferentes áreas geográficas do país. Pela magnitude das alterações, principalmente no segundo caso, entendemos ter havido mais de um fator de erro envolvido: punções repetidas no mesmo braço contra o esforço muscular da criança (provocado pelo medo na coleta), garroteamento prolongado, ocorrência de hemólise e provável atividade fisica prévia à coleta.

A partir desses fatos, reforçamos a necessidade de avaliar estas possibilidades com o laboratório de confiança do clínico, quando em presença de pacientes com dosagens elevadas de enzimas musculares sem um quadro clínico compatível. Em ambas as crianças já havia sido feito o diagnóstico de PM e prescrita corticoterapia em doses imunossupressoras, que apenas não foi seguida pela suspeição dos pais quanto ao diagnóstico.

Indicamos, em situações similares, a avaliação do procedimento da coleta pela anamnese com os pais, contato com o responsável técnico pelo laboratório de patologia clínica e repetição da avaliação laboratorial em condições ideais. Ressalvamos que o diagnóstico reumatológico é eminentemente clínico e que o diagnóstico de polimiosite juvenil não deve ser feito em bases puramente laboratoriais na ausência de quadro clínico compatível, princípio não adotado ao ser indicada corticoterapia em doses elevadas nos dois casos. Em outras palavras, tratou-se de exames e não de pacientes. 
Desta forma, ressaltamos alguns princípios de coleta para enzimas musculares:

1. evitar atividades físicas extenuantes nas 24 horas antes da coleta;

2. observar quatro horas de jejum antes da coleta;

3. usar garrote por tempo não superior a três minutos ${ }^{(5)}$;

4. nas coletas feitas com seringa e agulha, o sangue deverá ser transferido delicadamente para evitar hemólise, com o bisel da agulha em contato com a parede do tubo;

\section{REFERÊNCIAS}

1. Cherneck C, Krech R, Berger B: Laboratory tests and diagnostic procedures, Philadelphia, Saunders, 1993.

2. Henry J: Diagnósticos clínicos e tratamentos laboratoriais, 19.a ed, Philadelphia, Saunders, 1993.

3. Pagana K, Pagana T: Diagnostic and laboratory test reference, London, Mosby, 1997.
5. evitar consumo de álcool durante as 24 horas anteriores à coleta;

6. suspender drogas que possam interferir na análise dos resultados 24 horas antes da coleta (veja lista acima);

7. considerar que cirurgias e biópsias podem levar a resultados alterados;

8. medicações intramusculares devem ser suspensas;

9. efetuar nova coleta caso haja hemólise;

10. processar rapidamente as amostras, após a coleta.

4. Wu AH, Perry MB: Clinical applications of muscle enzyme and proteins. Curr Opin Rheumatol 4: 815- 20, 1992.

5. Chiu D, Wang HH, Blumenthal MR: Creatine phosphokinase release as a measure of tourniquet effect on skeletal muscle. Arch Surg 11: 71-4, 1976. 